2016-01-28

\title{
Bullying and harassment and
}

\section{work-related stressors: Evidence from British small and medium enterprises}

\section{Lewis, D}

http://hdl.handle.net/10026.1/9160

\subsection{7/0266242615624039}

International Small Business Journal

All content in PEARL is protected by copyright law. Author manuscripts are made available in accordance with publisher policies. Please cite only the published version using the details provided on the item record or document. In the absence of an open licence (e.g. Creative Commons), permissions for further reuse of content should be sought from the publisher or author. 


\title{
Bullying and harassment and work-related stressors: Evidence from British small and medium enterprises
}

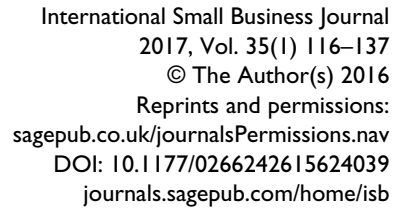

International Small Business Journal 2017, Vol. 35(I) 116-137

(C) The Author(s) 2016 Reprints and permissions: sagepub.co.uk/journalsPermissions.nav DOI: I0.1 I77/02662426/5624039 journals.sagepub.com/home/isb

(SAGE

\section{Duncan Lewis, Phil Megicks \\ Plymouth University, UK}

\author{
Paul Jones \\ Coventry University, UK
}

\begin{abstract}
This article examines the relationship between work-related stressors and bullying and harassment in British small and medium sized enterprises (SMEs). Using representative data from a national survey on employment rights and experiences (Fair Treatment at Work), this research identifies that bullying and harassment are just as prevalent in British SMEs as in larger organisations. Drawing upon the Management Standards of the Health and Safety Executive, a number of significant relationships with bullying and harassment are established. Work demands placed upon employees are positively related to bullying and harassment behaviours, while autonomy, manager support, peer support and clarity of role are negatively associated with such behaviours. The study considers implications for human resource practices in SMEs, and the risks of informal attitudes to these work-related stressors in contemporary workplaces are discussed.
\end{abstract}

\section{Keywords}

bullying, harassment, SMEs, work-related stressors

\section{Introduction}

Evidence from the 2004 (Forth et al., 2006) and 2011 (Bacon et al., 2013) Workplace Employment Relations Surveys (WERS) found a mixed picture for human resource (HR) practices in small and medium sized enterprises (SMEs) in the United Kingdom. Despite evidence for their widespread use, issues between employees and employers relating to trust, perceptions of fair treatment, satisfaction with training and development and job satisfaction varied significantly. Additionally, HR specialists existed in less than $30 \%$ of SMEs and were as low as $15 \%$ in owner-managed family businesses (Bacon et al., 2013). Employment relations in SMEs were demonstrated to be largely informal in the 2004 WERS data (Forth et al., 2006) and more recently (2011) has been shown to be part of the generic duties of managers and owners who spend $26 \%$ of their time on employment 
relations issues (Atkinson et al., 2014; Kitching et al., 2015; Van Wanrooy et al., 2013). One such employment issue is stress at work, with interest in work-related stressors growing significantly in the last 20-30 years (Cooper and Cartwright, 1997; Cox, 1993; Jones et al., 2003). Although workrelated stress has grown in prominence, Cocker et al. (2012) reported a shortage of SME-specific literature and research evidence on work stressors in SMEs. One of the few studies to address this is by Lai et al. (2015) who compared employee experiences in large firms with those in SMEs using data from the 2011 WERS study. Their results revealed work overload, job insecurity, weak promotion prospects and poor communication all negatively impact upon employee experiences in SMEs, while good work relationships have a positive impact.

These components have also featured in studies of workplace bullying where work-related stressors have been shown to be antecedents for bullying where excessive job demands, resource inadequacies and a lack of autonomy and job control can lead to severe bullying perceptions (Balducci et al., 2012; Notelaers et al., 2010). However, although interest in bullying and ill-treatment has received global attention (Einarsen et al., 2011; Fevre et al., 2012; Hoel et al., 2014; Lutgen-Sandvik and Tracy, 2012), as with stress research, work in SME contexts has been largely absent, except for one study by Baillien et al. (2011b).

This article brings these two topics together and analyses data from 1357 employees in SMEs who responded to a representative study concerned with employment rights (Fevre et al., 2009). Using previously unreported data from the second Fair Treatment at Work Study, the research presented here seeks to expand and develop knowledge on bullying and work-related stressors in SMEs. The study uses questions drawn from the UK's Health and Safety Executive (HSE) Management Standards and examines the impact of the following work-related stressors in relation to bullying and harassment: work demands (workload, work patterns and work environment), autonomy (how much control individuals have in the way they conduct their work), managerial support (including the support of managers and the organisation), peer support (the support of colleagues/other employees) and clarity of role (whether people understand what is expected of them and role conflicts).

In doing so, this research is responding to calls from researchers such as Baillien et al. (2011b) for evidence of workplace characteristics that might provide clarity in understanding bullying in an SME context and to Lai et al. (2015) who request enhanced understanding of mediating processes in perceived organisational support for role stressors in SMEs. The article enhances existing literatures on bullying and work-related stressors by furthering well-established conventions in an SME context. Furthermore, by providing evidence on the types of work-related stressors prevalent in SMEs, we aim to make a contribution to management and subsequent HR practices where ownermanagers, generalist managers and HR managers can use the findings to inform best practice.

\section{Bullying and work-related stressors}

In recent decades, interest in bullying and ill-treatment as problems that can be experienced in the workplace has risen in prominence and become widely recognised as global phenomena (Einarsen et al., 2011; Fevre et al., 2012). The terms bullying and harassment have been argued to be coterminous (Matthiesen, 2006), although harassment is often associated with protected characteristics such as gender, race, and sexual orientation (Hoel et al., 2014; Schneider et al., 2011). The close association of bullying with harassment is as a result of the repeated, persistent and damaging nature of the behaviours associated with them (Brodsky, 1976; Matthiesen, 2006). Bullying is concerned with unwanted negative behaviours that can range from minor harmless acts to severe actions (Jones et al., 2011). Two defining characteristics of bullying include, first, its persistency where individual negative experiences endure for considerable periods of time and involve a power imbalance between the parties where the target of bullying is often unable to defend themselves 
(Einarsen et al., 2011), and second, an inability to defend oneself may be a product of hierarchy (manager bullies subordinate) or where an individual has intimate knowledge of another's weaknesses and exploits them, for example, sexuality, ethnicity and disability (Fevre et al., 2013; Hoel, et al., 2014; Lewis and Gunn, 2007). It is the persistency and systematic mistreatment of individuals that leads to psychological, psychosomatic and social problems resulting in bullying being classified as a severe psycho-social stressor (Zapf et al., 1996).

Although research into bullying and harassment in SMEs is uncommon, Baillien et al. (2011b) demonstrated how an absence of people-oriented culture, poorly communicated organisational change and working in family businesses where change was taking place exacerbated the risks of bullying in SMEs, but that this could be buffered by an anti-bullying policy. Nonetheless, this presents challenges on policy enforcement and accountability where managers/owners can be selective in policy deployment and action, even though this now carries significant risks with employment legislation (e.g. Equality Act, 2010). While this might be countered by trade union representation, this presents problems for employees who are not members or who lack representative voice mechanisms (Saundry and Wibberley, 2014). Baillien et al.'s (2011b) research on Belgian SMEs did not cover the full spectrum of SME categories and was limited to organisations employing up to 100 employees using a sample of 358 respondents in 39 organisations. British studies reporting bullying by size of organisation, such as the 2009 Fair Treatment at Work Survey, revealed no significant differences in rates of bullying and harassment by organisation size (Fevre et al., 2009). Similarly, other research on the types of negative behaviours known to be associated with bullying was more prevalent in public sector workplaces and in larger organisations compared to smaller ones (Fevre et al., 2012). Despite this, research on depression among workers in SMEs revealed substantially increased scores for symptoms of depression and group conflict, arguing that the close proximity of relationships in SMEs and the subsequent deep connections between employees means that workplace conflicts become particularly pronounced (Ikeda et al., 2009). Bullying was positively associated with depression symptoms in a Japanese study (Giorgi et al., 2013), whereas team cohesiveness and supervisor support were negatively associated with bullying. Harvey et al. (2007) contend that bullying is affected by emotional contagion (see Ashkanasy, 2002; Hatfield et al., 1993 for definitions) as organisational cultures prevent effective intervention by managers and bystanders because individuals fear reprisals and being targeted (D'Cruz and Noronha, 2011). Further to this, Dundon et al. (1999) point to the close proximity of managerial authority in SMEs as a route to reprisals against employees, and researchers have long argued that assumptions that SME employees and owners have shared aspirations thus bypassing the need for collective representation is too simplistic (Marlow and Patton, 1993); and that human resource management (HRM) practices in SMEs can somehow be a substitute for trade union representation (Harney and Dundon, 2006). The continued decline of trade union membership among the general working population (Van Wanrooy et al., 2013) and the scepticism and antipathy with which they are viewed by owners/managers in SMEs (Dundon et al., 1999; Forth et al., 2006) make adequate representation for targets of workplace bullying extremely challenging, despite evidence showing that good employer-union relationships provide more nuanced routes to conflict dispute resolution (Saundry and Wibberley, 2014). Thus the existence of a poor workplace climate where bullying, harassment, tension between colleagues, strained working relationships and poor voice representation are clearly work-related stressors. Our article now turns to explore the HSE Management Standards components with the aim of producing research questions and hypotheses.

The work environment has long been shown to be associated with bullying and other forms of ill-treatment, where stressful work environments increase conflicts such as bullying (Salin and Hoel, 2011). Conflicts in work relationships feature in work undertaken by the UK's HSE that first developed its employers guide in 1995 in an attempt to tackle stress in UK workplaces (HSE, 
1995). Later, development of this work led to the current 'Management Standards' taxonomy (Mackay et al., 2004) where a range of work-related factors were established as the basis for tackling workplace stress. Adopting a structured approach of identifying hazards, harms and risks (Mackay et al., 2004), the HSE developed an Indicator Tool of 35 items which have been shown to be an acceptable fit as a possible single measure of work stress (Edwards et al., 2008).

Work-related factors of job control and work demands feature strongly in theories of workrelated stress, with a model proposed by Karasek (1979) using the Job-Demands-Control model central to our understanding. Job or work demands include workload, irregular work tasks, as well as work relationships, while control refers to how much autonomy or discretion an individual has over work tasks (Baillien et al., 2011c). High job demands and low control equate as stressors, while high control attenuates job demands (Baillien et al., 2011c). Task variety, autonomy in decision-making, increased trust and support and reduced physical strain have been shown to impact positively on job satisfaction, motivation and wellbeing (Cox et al., 2012). Researchers have demonstrated the salience of the work environment as one of the primary antecedents for bullying (Baillien et al., 2009; Balducci et al., 2012; Hauge et al., 2007; Matthiesen and Einarsen, 2004; Notelaers et al., 2012). Recent studies from Balducci et al. (2012), Notelaers et al. (2012) and Reknes et al. (2014) demonstrate role conflict, role ambiguity and excessive and incompatible work demands were associated with bullying. Furthermore, Salin (2015) and Skogstad et al. (2011) noted how a poor physical working environment and social climate not only lead to subjection to bullying but also to observation of bullying. Thus, while many studies exist in the literatures on bullying and the work-environment hypothesis, few, if any, report organisational size. This leads to the presentation of the first hypothesis:

Hypothesis 1: The work demands placed on employees in their work are positively associated with the incidence of bullying and harassment in SMEs.

The amount of autonomy an individual has over their work environment has been demonstrated as a key stressor, where high levels of autonomy are associated with high job satisfaction, commitment, involvement, motivation and performance, and low levels of autonomy with symptoms of distress, role stress and intentions to quit (Spector, 1986). Similarly, breaches in the psychological contract where an employee perceives decreased job responsibilities and opportunities for personal growth are likely to lead to disruptive behavioural responses (Kickul, 2001). In research on illtreatment at work, evidence showed that having less autonomy and the presence of super-intense work were significant risk factors for perceived ill-treatment (Fevre et al., 2011). Low or poor job autonomy has been argued to be associated with bullying (Einarsen et al., 1994; Vartia, 1996; Zapf et al., 1996), although Notelaers et al. (2010) did not find a relationship with task autonomy. Baillien et al. (2011a) demonstrated how job autonomy was an antecedent rather than a consequence of bullying, suggesting that job design was crucial if organisations are to attempt to reduce bullying. Baillien et al. (2011a) and Notelaers et al. (2012) confirmed that high-strain/high-demand jobs led to risks of employees becoming targets of bullying. Additionally, Baillien et al. (2011a) reported that employees in such situations can also become perpetrators of bullying, thus perpetuating the potential for a harassing work environment, and Lai et al. (2015) identified higher levels of autonomy among SME employees mitigated the risk of stress in SMEs. Thus, the second hypothesis for investigation is

Hypothesis 2: The autonomy that employees have over their work is negatively associated with the incidence of bullying and harassment in SMEs. 
Significant evidence exists that demonstrates most bullying and ill-treatment is likely to be attributed to manager/supervisor behaviours (Fevre et al., 2009, 2012; Hoel and Beale, 2006; Rayner et al., 2002). With work demands primarily emanating from managers through work tasks, there is clear potential for correlation. Yet, managers themselves are often victims (Branch et al., 2012; Fevre et al., 2012), leading Beale and Hoel (2011) to conclude that the challenges of tackling bullying are manifest when both perpetrator and target are from the same occupational group, and where managers hold the primary responsibility for administering and actioning policies. With the absence of HR specialists in many SME organisations (Bacon et al., 2013) and with employment relations responsibilities having been shown to be the responsibility of general managers in $79 \%$ of SME organisations in the 2011 WERS survey (Van Wanrooy et al., 2013), evidence of the duality of managers as bullies and peacemakers is problematic.

Previous research suggests that this is compounded when an absence of social support from colleagues and managers is positively related to bullying, while direct support from peers in the workplace is negatively associated with bullying (Bentley et al., 2009; Hogh et al., 2011; Lewis, 2004; Woodrow and Guest, 2013). D'Cruz and Noronha (2011) established that when co-workers who are friends of bullied victims offer support, they become drawn into the role of 'bystander victim' leading to withdrawal of support because of supervisor reactions and organisational positions. This abandoning of friendships at work left bystanders 'experiencing emotional turmoil because of their inaction' (D'Cruz and Noronha, 2011: 286). Lutgen-Sandvik et al. (2007) identified that bystanders also deployed non-intervention strategies, simultaneously reporting lower levels of job satisfaction and higher levels of stress; while Emdad et al. (2013) revealed that bystanders of bullying developed risks of the symptoms of depression. The limited evidence on stress in SMEs has demonstrated that proximity to, and trust in, management support leading to good working relationships reduces the potential for stress in SMEs, possibly because of closer proximity of employee to managers and owner-managers in this context (Lai et al., 2015). Social support was also found to lessen the effects of stress among entrepreneurs and their employees (Chay, 1993). Thus, the clear evidence of managers simultaneously acting as perpetrators and potential victims, the interaction effects of bystanders witnessing bullying and the broad importance attached to support in alleviating bullying lead to the third and fourth hypotheses of the study:

Hypothesis 3: The extent of manager support available to employees is negatively associated with the incidence of bullying and harassment in SMEs.

Hypothesis 4: The extent of peer support available to employees is negatively associated with the incidence of bullying and harassment in SMEs.

Broadly, role clarity, role ambiguity and role conflict/role control affect job satisfaction and work stress (Jackson, 1983). Role conflict and role ambiguity are argued to be strong predictors of bullying (Einarsen et al., 1994; Notelaers et al., 2010, 2012; Reknes et al., 2014), and when employees perceive conflicting demands and expectations in work roles that are unpredictable, perceptions of bullying exist. Hauge et al. (2007) illustrated a strong correlation between role conflict and laissez-faire leadership behaviour with bullying leading them to conclude that "negative interpersonal interaction is indeed more harmful to employees than supportive behaviour is helpful' (p.236). This leads to the fifth hypothesis:

Hypothesis 5: The clarity of employees' role is negatively associated with the incidence of bullying and harassment in SMEs. 


\section{Research methods}

\section{Data and sample}

The data upon which this article is constructed were collected on behalf of the UK Government (Department for Business, Enterprise and Regulatory Reform). Titled 'The Fair Treatment at Work Survey', the investigation gathered views on awareness of employment rights, workplace problems, sources of support to employees and how work problems are resolved. Modelled on previous employment rights surveys undertaken in 2005 - the Employment Rights at Work Survey and the First Fair Treatment at Work Survey - the research used an Omnibus Survey based on a stratified sample of two waves of 2000 adult employees working in British workplaces (Northern Ireland was not included).

The investigation was conducted by Taylor Nelson Soffres (TNS) and data from the main survey reported by Fevre et al. (2009). The sample was selected to be representative of the general population and interviews were conducted in private households with eligible respondents - those who were in paid work or had been within the last 2 years (the self-employed were excluded). Eligibility to participate was determined by the following question:

Have you/Have any of these people had a paid job at any time in the last two years, either on a permanent basis or as a temporary employee or worker, fixed term, casual or agency worker? Please do not include anyone who has only worked abroad or on a self-employed basis or as a Managing Director of their own company.

(TNS, 2008: 5)

A total of 4010 interviews were carried out for the initial phase, and a further 3608 respondents accepted an invitation to take part in a self-completion/secondary survey. It is this secondary selfcompletion survey that this article is based upon, which hitherto has been unreported. This study uses the standard definition of the European Commission (EC) classification for SMEs as enterprises employing fewer than 250 employees (EC, 2003). The data were cleaned and cases with excessive missing responses were removed, leaving 1357 fully completed questionnaires for analysis in the SME category.

\section{Respondent and organisational characteristics}

Table 1 presents the characteristics of the sample in terms of individual respondent's personal demographics and employment situation. Further characteristics were established for the organisations in which respondents were employed.

Comparative statistical tests were used to ascertain whether there were any significant differences between the characteristics of respondents employed in SMEs in the study and those in the main survey of all organisations. The relevant tests based upon the nature of the measures employed (categorical, ordinal and numeric) identified no significant disparities in the demographic and employment-related characteristics, and it can therefore be determined that there are no significant differences between individuals who work in SMEs and larger organisations.

\section{Analyses}

\section{Procedure}

Questionnaire data were collected using 5-point Likert scales for 31 items representing a series of work-related stressor influences that may affect the incidence of bullying and harassment in organisations, together with two items asking whether respondents were subject to bullying and 
Table I. Respondent characteristics $(N=1357)$.

Characteristics of sample

$\%$ of Respondents

Employee characteristics

Age

$<35$ years

25

$35-55$ years

50

$>55$ years

25

Gender

Male

59

Female

41

Supervisory responsibility

Yes

40

No

60

Tenure

$<2$ years

29

$>2$ years

71

Contract type

Permanent

93

Temporary

Working status

Full time

71

Part time

29

Trade union membership

Yes

29

No

71

Organisation characteristics

Enterprise size

Micro (I-9 employees) $\quad 25$

Small (10-49 employees) $\quad 40$

$\begin{array}{ll}\text { Medium (50-249 employees) } & 35\end{array}$

Sector

Primary

4

Secondary

10

Tertiary

86

Family business

Yes

15

No

85

Trade union representation

Yes

37

No

63

harassment at work. Bullying was measured by the statement 'I am subject to bullying at work' and harassment measured by 'I am subject to personal harassment in the form of unkind words or behaviour at work'. The 31 statements originate from the HSE's 'Management Standards' (2008) (http://www.hse.gov.uk/stress/standards/).

Data were analysed using SPSS, initially employing exploratory factor analysis to identify a set of variables from the work-related stressor item battery that influence bullying and harassment, and a joint construct measuring the incidence of bullying and harassment. Reliability of the factor 
variables was then assessed using Cronbach's coefficient alpha. Subsequently, tests for common method variance were undertaken. Following this correlation, hierarchical multiple regression analyses were undertaken to establish the relationships and degree of association between a number of control variables and each of the identified stressor factors on the incidence of bullying and harassment.

\section{Identifying the work-related stressor variables influencing bullying and harassment}

Exploratory factor analysis using a principal components extraction with varimax rotation (Kline, 2000) was implemented to establish the identifiable stressor factors. Having recognised six factors using the Eigen value and scree plot protocols, corrected item-to-total correlations between items were then examined, which led to all the original items being retained and taken forward to the next stage of analysis ( $>0.5$, Field, 2009). The rotated component matrix presented an evident and substantively explainable set of factors. The six-factor solution accounted for approximately $62.6 \%$ of total variance and exhibited a Kaiser-Meyer-Olkin (KMO) measure of sampling adequacy of 0.94 . The communalities ranged from 0.44 to 0.83 . Table 2 displays the rotated component solution for the bullying and harassment influences and outcomes.

The first component identified was 'Managerial Support', which accounts for $32.64 \%$ of total variance explained, and represents different aspects of managerial support within the workplace. It comprises eight items with a Cronbach's $\alpha$ coefficient value of 0.91 . This shows a high level of consistency in the scale being greater than the generally agreed lower limit of 0.70 (Hair et al., 2010). The second component 'Work Demands' (accounting for $8.86 \%$ of total variance explained) comprises seven items $(\alpha=0.85)$ representing the ways that workers perceive pressures upon them in their work environment. 'Clarity of Role' explains $7.37 \%$ of total variance and comprises five items $(\alpha=0.87)$. It indicates how clear employees are about what is expected from them in the work environment and was identified as the third component. The fourth component that explains $6.26 \%$ of total variance in the model is labelled 'Autonomy' $(\alpha=0.84)$. It represents how much autonomy and control an individual employee has over their work role and is made up of six items. The fifth component 'Peer Support' $(\alpha=0.83)$, comprising four items, accounts for $4.07 \%$ of total variance explained, and indicates the amount of support forthcoming from co-workers. The final component is a two-item combined scale measuring Bullying and Harassment $(\alpha=0.81)$, and explains $3.40 \%$ of model variance.

\section{Common method analysis}

As the same informants provided responses to the questions that related to both the dependent and independent variables in the study, there is potential for concern with regards to common method variance in the data (Podsakoff et al., 2003). To address this issue of measures being derived from a common source, an approach was adapted from similar studies of SMEs (Boso et al., 2013) that utilises several procedures and statistical tests to assess the presence of common method bias (Chang et al., 2010). The questionnaire design included questions that were mixed in order, included reverse coding items, and a guarantee of complete confidentiality was given to respondents. Harman's single-factor test was undertaken where all items were loaded on one factor in an exploratory factor analysis. This resulted in only $29.38 \%$ of the variance being loaded on the single factor, which is not a cause for concern as no single factor emerged from the data. Subsequently, two competing confirmatory factor analysis (CFA) models were estimated to take account of possible common variance. Initially, a method-only model was developed, where all items represented indicators of a single latent factor: $\chi^{2} / \mathrm{df}=20953 / 434=48.27$; root mean square error of 





approximation $($ RMSEA $)=0.159$; Tucker-Lewis Index $(\mathrm{TLI})=0.27$; comparative fit index $(\mathrm{CFI})=0.27$. The second model was a trait-only model in which each indicator was loaded on the respective identified latent factors: $\chi^{2} / \mathrm{df}=3043 / 395=7.71$; RMSEA $=0.60 ; \mathrm{TLI}=0.90 ; \mathrm{CFI}=0.91$. Comparison of the two models shows the first single-factor model as having an extremely poor fit, whereas the second multi-factor trait model is far superior with respect to this. As such, it is possible to conclude that common method bias is not substantially represented in the data and is therefore not a significant concern in the study.

\section{Control variables}

Consistent with previous studies, a set of control variables was included in the analyses to ensure that variability associated with particular demographic, employment-related and organisational characteristics that have been identified as potentially affecting the incidence of workplace bullying and harassment are taken account of across the sample (Baillien et al., 2011b, 2011c, 2012; De Cuyper et al., 2009; Einarsen and Skogstad, 1996; Hoel and Beale, 2006; Rayner, 1997; Zapf et al., 2003). Moreover, establishing the effects of these variables in the first instance makes it possible to evaluate the unique effects of the work-related stressor variables.

The control variables were categorised as employee and organisational factors. In relation to the employee, controls were included for gender, age, supervisory responsibility, tenure (less than 2 years/2 years or more), contract status (permanent/temporary), working hours (full time/part time) and trade union membership. Additionally, the organisational characteristic controls included size (micro/small/medium), sector (primary/secondary/tertiary), family business and trade union representation. For all of these except age, which was measured as a continuous variable, dummy variables were created (using 1 and 0 codes). For the organisational size factor, two dummy variables were developed, one to take account of a comparison between micro-businesses ( $0-9$ employees) as the baseline variable and small enterprises (10-49 employees); and another to take account of micro-businesses as the baseline and medium sized enterprises (50-249 employees). Similarly, for the sector category, two dummy variables were created, first for secondary industries and second for tertiary services, both in comparison with the primary sector as the baseline.

\section{Analysis of work-stressor influences on bullying and harassment}

Within organisations, a range of influences on bullying and harassment have been established and it is possible to analyse the extent to which each of these affects bullying and harassment as a joint construct. Correlation and multiple linear regression analysis using the enter method was utilised to achieve this. The independent variables submitted into the model were the five stressor factors derived from the principal component analysis, plus the two sets of control variables identified above. To establish the specific effects of the different sets of factors and, in particular, the work stressors on the dependent variable, a hierarchical modelling approach was used (Cohen et al., 2014). This approach enters independent variables in sequential blocks and develops different models to assess their effects on the independent variable. Consequently, the analysis constituted three models that entered the employee control variables, first; second, the organisational control variables were added; and third, the work-related stressor variables were included. The models were then compared for their explanatory power of variation in the dependent variable together with the significance of the effects of each of the factors. From such an analysis, it is possible to identify the separate associations of the employee factors and the organisational factors as well as those of the individual work-related stressors that relate specifically to the hypotheses that have been presented for investigation. 


\section{Results}

\section{Incidence of bullying and harassment and correlations}

The level of bullying and harassment based upon the responses to the two relevant questionnaire items is presented in Table 3. The mean score for bullying at work on a 5-point scale was 1.25 (standard deviation $(\mathrm{SD})=0.69)$, and for bullying $1.54(\mathrm{SD}=0.92)$. These findings indicate that employees working in SMEs have a level of exposure to bullying of $7.0 \%$ (composite of sometimes, often and always), and similarly for harassment with $15.0 \%$ reporting the same outcomes. The figures are comparable with those for larger organisations with over 250 employees $(7.5 \%$ bullying; $14.8 \%$ harassment), and the wider working population across organisations of all sizes (7.2\% bullying; $15.6 \%$ harassment) (Fevre et al., 2009).

Table 4 presents the means, SDs and correlations between the study variables. There are highly significant statistical correlations between all five work-related stressor variables and bullying and harassment, with one (work demands) being positively related, whereas the remaining four are negatively associated (all $p<0.01$ ). Of the control variables, there are three significant correlations with bullying and harassment all at the $p<0.05$ level. These indicate that the incidence of bullying and harassment is significantly more associated with full-time workers compared with part-time workers. Similarly, there are significant associations between personal employee trade union membership and the organisation having trade union representation, and bullying and harassment.

\section{Hierarchical regression analysis}

The results of the hierarchical regression analysis are reported in Table 5 and illustrate the relationships between the aggregate bullying and harassment dependent variable and the employee and organisational control variables, plus the work-related stressor factors. The analysis was undertaken as a set of sequential hierarchical models to determine the significance of each factor and the blocks of variables entered.

The results of Model 1 for the employee factors as independent variables show two significant and positive associations with bullying and harassment: working status with full-time employment being a highly significant factor $\left(\beta=.118^{* * *}\right)$ associated with bullying and harassment, and Trade Union membership $\left(\beta=.082^{* *}\right)$ very significantly related to the same outcome. The model has an $R^{2}$ of $.023\left(F=4.456^{* * *}\right)$. Adding the organisational factors in Model 2 identifies the size effects for small compared with micro-enterprises $\left(\beta=.021^{*}\right)$, and medium sized enterprises compared on the same basis $\left(\beta=.026^{*}\right)$, as being significant in explaining variation in the bullying and harassment dependent variable; these are in addition to rather similar effects for the two significant factors in the first model. Model 2 has an $R^{2}$ of $.029\left(F=3.055^{* * *}\right)$, but the $R^{2}$ change (.006) is not significant and therefore adds very little to the model's overall explanatory capacity. Finally, the work-related stressor factors were added in Model 3. In this model, none of the control variables from the original two models are significant, but all of the additional variables increase significantly the explanatory power of the model, with each one being significant in its association with variation in the dependent variable. Managerial Support $\left(\beta=-.156^{* * *}\right)$ and Peer Support $\left(\beta=-.122^{* *}\right)$ have highly significant negative effects, with Autonomy $\left(\beta=-.091^{* *}\right)$ and Clarity of Role $\left(\beta=-.076^{* *}\right)$ being very significant in the same direction. Whereas Work Demands $\left(\beta=177^{* * *}\right)$ is highly significant and positively associated with bullying and harassment incidence. The addition of these work-related stressor variables leads to a highly significant increase in the model's ability to explain the overall variance in the dependent variable with the $R^{2}$ increasing from .029 to .229 . This gives an increase of .200 which is significant at the $p=.000$ level, and results in a highly significant explanatory model $\left(F=21.840^{* * *}\right)$. The analysis reveals that the 
Table 3. Incidence in bullying and harassment descriptive results.

\begin{tabular}{lllllll}
\hline $\begin{array}{l}\text { Questionnaire item, } \\
\text { response frequencies } \\
(N=1357)\end{array}$ & Never (I) & Seldom (2) & $\begin{array}{l}\text { Sometimes } \\
(3)\end{array}$ & Often (4) & Always (5) & Mean (SD) \\
\hline $\begin{array}{l}\text { I am subject to bullying } \\
\text { at work }\end{array}$ & $1153(85.0 \%)$ & $108(8.0 \%)$ & $64(4.7 \%)$ & $18(1.3 \%)$ & $14(1.0 \%)$ & $1.25(0.69)$ \\
$\begin{array}{l}\text { I am subject to personal } \\
\text { harassment in the form } \\
\text { of unkind words or } \\
\text { behaviour at work }\end{array}$ & $917(67.7 \%)$ & $235(17.3 \%)$ & $145(10.7 \%)$ & $34(2.5 \%)$ & $26(1.8 \%)$ & $1.54(0.92)$ \\
\hline
\end{tabular}

SD: standard deviation.

addition of the work-related stressor factors into the hierarchical model building process provides greater insight (an increase of 20\%) into the understanding of variation in bullying and harassment between SMEs compared with the employee and organisational control variables.

The high levels of association of the work-related stressors with bullying and harassment explained in the final regression model presents strong evidence to support all of the study's hypotheses. Thus, Hypothesis 1 that proposes a positive association of work demands with bullying and harassment can be supported. In addition, Hypotheses 2, 3, 4 and 5 that propose negative associations of autonomy, manager support, peer support and clarity of role, respectively, with bullying and harassment can all be supported. Further results of the analysis of the earlier models suggest that full-time employees and Trade Union members have a greater association with bullying and harassment compared with part-time employees and non-members of Trade Unions, respectively. There is also some size of enterprise effects evident that suggest that smaller microSMEs with fewer than 10 employees have a lower association with bullying and harassment compared with the larger SMEs in the study. All these effects are however not evident in the final superior model which identifies the five work-stressor factors as the key drivers of differences in bullying and harassment in SMEs.

\section{Discussion}

The research presented here examines the relationship between employees working in British SMEs and a range of work-related stressors relating to bullying and harassment. Using a data set designed to measure employment problems in British workplaces, we find that employees working in SMEs are as likely as employees working in larger organisations to encounter bullying and harassment. Some 7\% of SME respondents reported occasional and regular exposure to bullying and more than double this number $(15 \%)$ for harassment. These are directly comparable to UK representative studies on bullying and ill-treatment, illustrating the pervasive nature of these problems (Fevre et al., 2009; Fevre et al., 2010; Hoel and Cooper, 2000). In SMEs, this is likely to be particularly troubling for an employee as voicing concerns could result in them being labelled a troublemaker or a misfit because of the close proximity of owner/manager to their workforce, which 'pressurises the owner into reasserting authority in a covert manner', particularly for disciplining employees (Marlow and Patton, 2002: 527). Following our conceptual development that identified that work-related management standards associated with stress might create the conditions that affect the incidence of bullying and harassment, we formulated five hypotheses. The regression analysis revealed that all five of the identified factors have a significant association with bullying and harassment in SMEs with the predicted direction of effect being supported from the original 


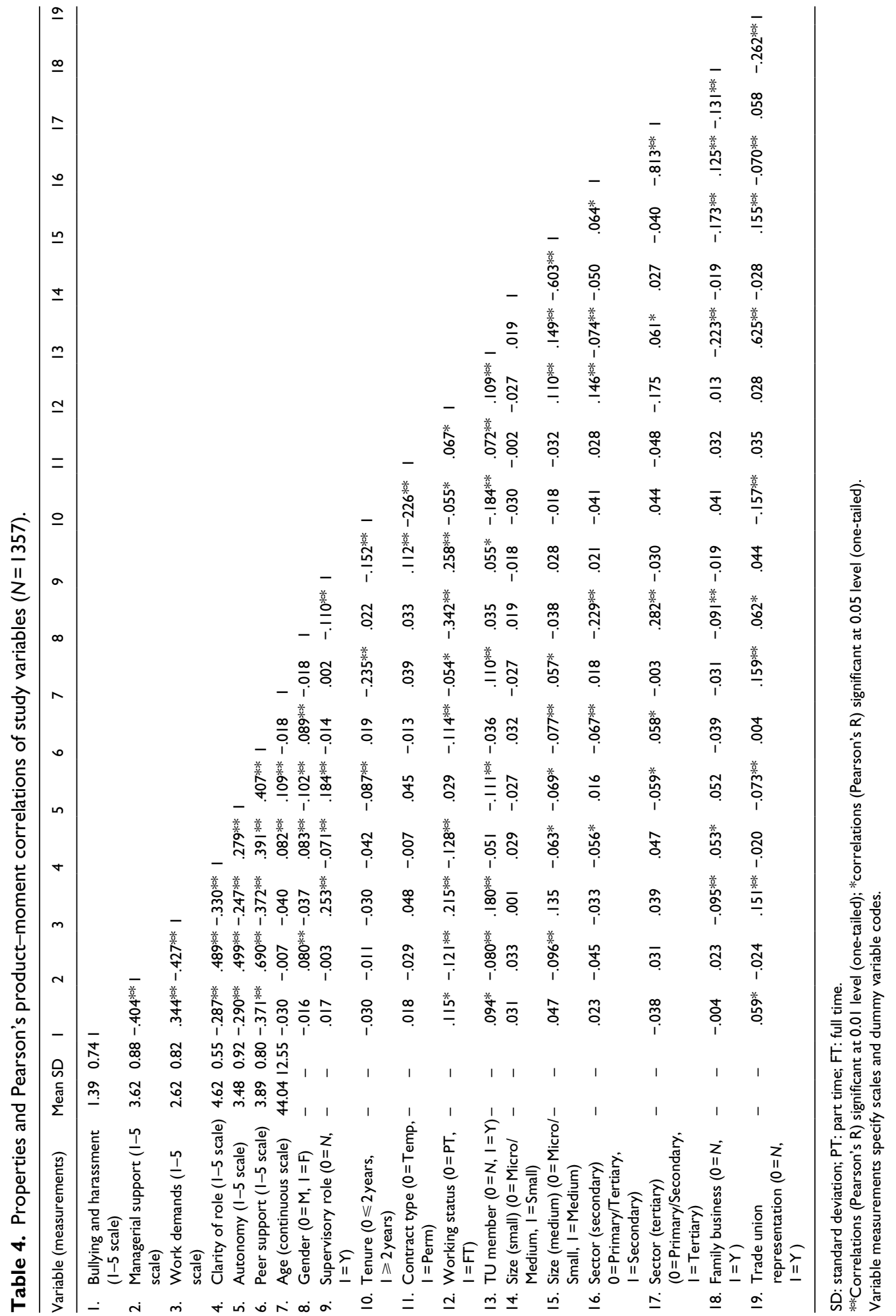




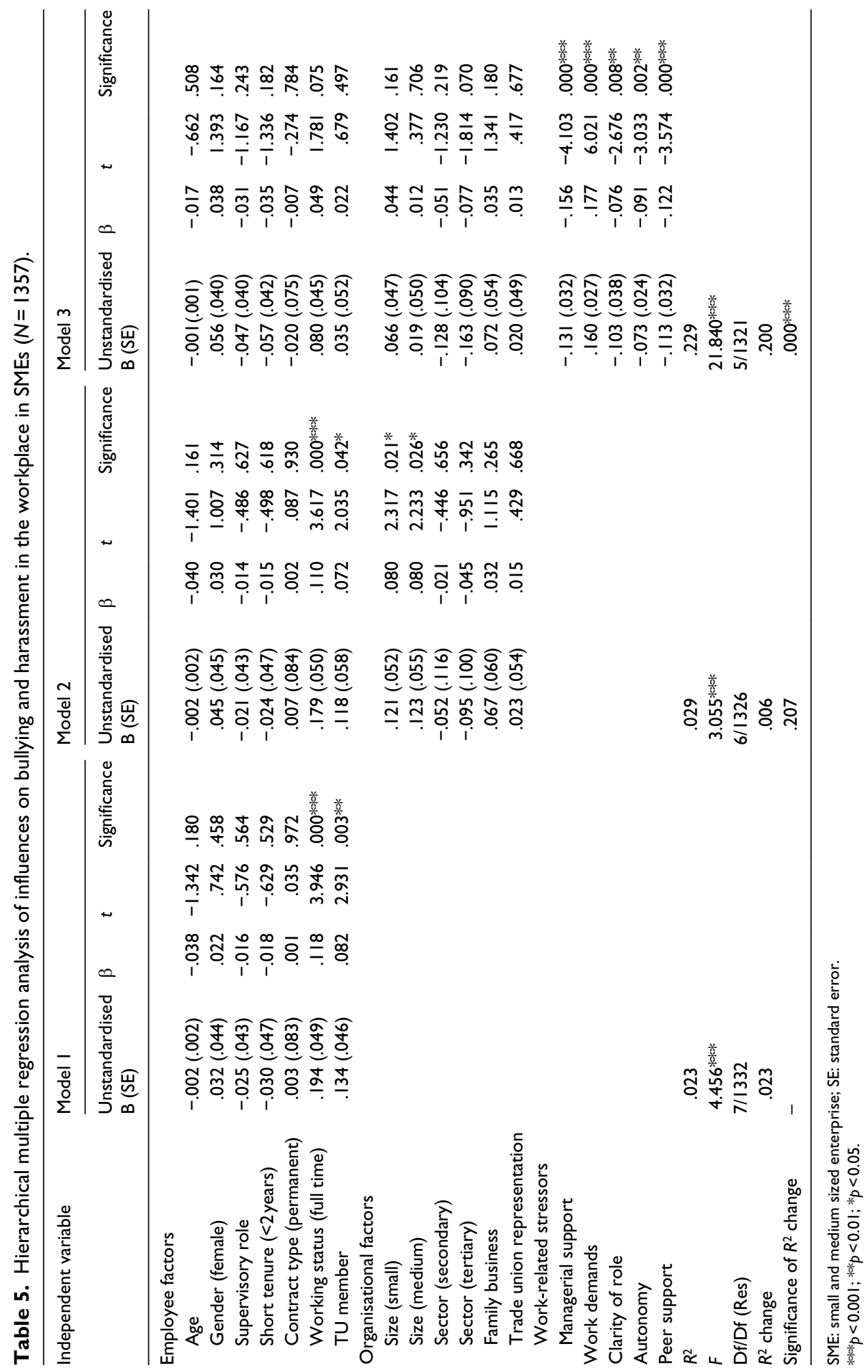


hypotheses. In sum, 'Work Demands' is positively associated with bullying, while the hypotheses relating to the proposed buffers of bullying and harassment - 'Autonomy', 'Managerial Support', 'Peer Support', and 'Clarity of Role' - are all supported with a significantly negative outcome.

These findings are supported by existing literature which found pressured work environments, with excessive job demands and poor job control, are positively associated with bullying (Balducci et al., 2012; Einarsen et al., 1994; Hauge et al., 2007; Notelaers et al., 2012; Reknes et al., 2014). Work demands are by default the responsibility of owners/managers and supervisors and the flat structures and broader spans of control found in SMEs, that is, smaller hierarchies and broader and more informal responsibilities, (O'Regan and Ghobadian, 2004), compared to larger organisations might have some bearing in this regard, particularly as our results show an association with lower levels of bullying in very small organisations (fewer than 10 employees). Baillien et al. (2011b) suggest that SMEs should, in theory, be more effective at dealing with work disputes such as bullying because of the closer operating environments of owners/managers to employees. This is partly confirmed by showing that the incidence of bullying may be reduced, where manager and co-worker supportive cultures exist. However, Baillien et al. (2011b) did not show bullying to be associated with a task or performance based culture. We would suggest that SME owners/managers are just as responsible for making sure employees are clear about what is expected of them and that there are benefits from doing so. Clarity of an employee's role through effective job design, clear expectations of performance, effective management and unambiguous leadership has been shown to be important antecedents in mitigation of bullying (Einarsen et al., 1994; Notelaers et al., 2010; Skogstad et al., 2011). Clarity of responsibilities should, in theory, be clearer in the flatter structures of SMEs, where owners/managers operate in close proximity to the workforce and should therefore be a relatively easily attained objective.

We have demonstrated in this research that autonomy at work and the ability to control the pace and timing of work tasks are strongly and negatively associated with bullying in SMEs, and this is supported among general workplace populations (Baillien et al., 2011a; Einarsen et al., 1994; Notelaers et al., 2012; Zapf et al., 1996). As Zapf et al. (1996) suggest, when work conflicts arise, having less control over work tasks means that finding the time to resolve disputes is also diminished. In SME contexts, where colleagues work in smaller organisational units, owners/managers are much closer to the working environment and it is feasible to foresee situations where their proximity means greater levels of interference in organising and managing work tasks, particularly where resistance to management pressures has been shown in some cases to be classed as undermining social cohesion (Marlow and Patton, 2002). Similarly, with the need for more flexible labour in SMEs where resources are less plentiful, control over the types and timings of work undertaken become much more challenging for employees leading to them being 'worn out' (Baillien et al., 2011d). As Einarsen et al. (1994) demonstrated, 'role conflict and work control are the most important factors in predicting such experiences [bullying and harassment] at work' (p.295).

As reported in other studies of bullying and harassment (Lewis and Rayner, 2003; Bentley et al., 2009; Hogh et al., 2011), employee and manager support are important determinants in whether bullying flourishes or not in all organisations, but particularly so in SMEs. With redress being potentially financially expensive and with corporate reputational costs being unseen, but equally or even more damaging, ensuring front line managers and other employees are aware of rights and responsibilities makes sound economic sense. Our findings indicate that both types of support are associated as important buffers for both bullying and harassment and one would reasonably expect this to be more easily attainable in SMEs for the reasons already identified. However, Baillien et al. (2011b) suggest that a key determinant for bullying in SMEs was the potential shortage of economic resources, meaning that long-term strategies and policies for employee problems at work 
become secondary in importance. Believing that bullying in SMEs is a minor issue could prove very costly indeed. In keeping with this, the absence of employee voice mechanisms in many SMEs (Harney and Dundon, 2006; Marlow and Patton, 2002) means that routes to employee support may not be as readily available as might be assumed. Nevertheless, the findings in this study that trade union members in SMEs have a greater association with bullying and harassment is echoed in other studies (Hoel and Cooper, 2000; Lewis, 1999) partly because they are likely to be more effectively informed on employment rights and have access to expert resources. The results also demonstrate that full-time employees in SMEs associate more with bullying and harassment than part-time employees and this might be a product of more regular and frequent exposure to the work-related stressors that appear to be central antecedents to bullying and harassment behaviours.

\section{Limitations}

As previously indicated, the authors had no control over the research design and question structure. Like many studies that report on bullying, the cross-sectional nature of the study does not allow for causality. There is the possibility however of reverse causality as workers who encounter bullying see this as a destructive conflict which might lead to greater role conflicts and subsequently less support from colleagues and managers (Leon-Perez et al., 2015), as well as concomitant increased job demands and reduced autonomy (Tepper, 2000). All studies of bullying and harassment would benefit from longitudinal designs, but social science research on such topics, especially in sectors such as SMEs, are often poorly resourced and fraught with access difficulties.

We also believe it would be beneficial to adopt more conventional definitions of bullying and to test this among SME populations in a range of cultural contexts. Similarly, exploring a spectrum of negative behaviours as outlined in instruments such as the Negative Acts Questionnaire (Einarsen et al., 1994) or British Workplace Behaviour Scale (Fevre et al., 2011) might provide more insights into the types of behaviours experienced in SMEs. Our results show an association between bullying and trade union membership which contrasts with the study by Baillien et al. (2011b). Further analysis may therefore be required to explore the patterns, correlates and antecedents of bullying and harassment in unionised and non-unionised SME populations as well as other indicators such as employment status, particularly in the changing labour market conditions increasingly found globally.

Finally, there is clear evidence in previous studies (Hoel and Cooper 2000; Lewis and Gunn, 2007) that minority status is likely to lead to higher prevalence rates of bullying and harassment. Even in a representative sample such as the one used in this study, numbers of respondents in the demographic minorities categories are often too small to undertake statistical analyses. It might therefore be timely to encourage membership bodies that represent SMEs, such as the Federation of Small Business in the United Kingdom, to include questions on bullying and the negative behaviours that underpin it in their large surveys of members.

\section{Conclusion}

The results of this study suggest that it is in the optimum interest of SMEs to allocate some resource to tackling bullying and harassment as there are key benefits for doing so. Whether this falls to someone with HR responsibilities or not is debatable, although Sheehan (2014) and Verreynne et al. (2011) have both demonstrated the value of HR practices to SMEs. It can be argued that this might be through policy, training or other intervention strategies, but a key driver is that owners/managers and colleagues hold the key to implementing countervailing action. This nevertheless presents a fundamental challenge to SMEs because as Beale and Hoel (2011) 
concluded managers can be both victims and perpetrators. This suggests that in the absence of HR functions in SMEs, or where owners/managers operate with multiple identities, including people management responsibilities, the importance of policy and clarity of process is critical (Kitching, 2015). Employees who encounter bullying, regardless of the size of organisation they work in, are limited to resolutions and interventions including management, HR, trade unions, intermediaries such as Acas, law firms or Citizen Advice Bureaus. This places significant emphasis on policy and process as these are default positions that the courts would turn to for signs of fairness being enacted. Although owners/managers are often the ultimate decision makers, questions remain about their expertise to make appropriate decisions for the welfare of their employees. This emphasises the need for a HR or independent specialist to undertake investigations into bullying and ill-treatment to ensure employees are fairly treated and the organisation is not placed at litigious risk.

The 2010 Equality Act makes harassment and victimisation illegal, and unlike many previous pieces of employment legislation, it affects all organisations, regardless of size. Thus, an absence of policy or training to tackle bullying and harassment is likely to be troublesome for SMEs in the face of employment litigation situations. In the event these involve circumstances that invoke protected characteristic status, these could prove very expensive for employers as there are no upper compensation limits on discrimination. Despite this, the current UK government has stifled legal redress for employees by introducing payment (in 2013) for having a case heard at Employment Tribunal, costing up to $£ 1200$. Such moves to curb routes to injustice have received widespread support from employer groups and their introduction has seen a $64 \%$ decrease in the year following their introduction (Pyper and McGuiness, 2015).

The research presented here has demonstrated that bullying and harassment are not solely the domain of large organisations. The existence of both dimensions of this unfair treatment of employees in SMEs at levels directly comparable to larger firms is strongly correlated with the working environment hypothesis proposed by Einarsen (2000) and Leymann (1996) among others. In response to Baillien et al. (2011b) who called for more research into the job characteristics associated with bullying in SMEs, this study has responded and extended general understanding by examining the full range of SME size classifications.

This article has clear implications for practitioners. It provides contemporary understanding of work-related stressors in SMEs and how these can underpin as well as deter bullying and harassment. This can assist owners/managers to redouble their efforts in arriving at effective job and work design, considered work demands/work controls and increased autonomy and manager/ employee support. As Lai et al. (2015) have identified, work demands must match the capabilities and resources of those undertaking the tasks if work overload is to be prevented. As such, the interactions of owners/managers and co-workers in understanding how bullying and harassment is a bi-product of the work environment necessitates SMEs actively encouraging interactions between owners, managers and employees to tackle it. While there is evidence to suggest that informality is valued by SMEs (Saridakis et al., 2013) and that flexibility is key to their existence (Sheehan, 2014), Storey et al. (2010) concluded that all formality should not be excluded in SMEs 'because extreme informality can be a cover for autocracy' (p.318). Furthermore, Saridakis et al. (2013) concluded that SMEs might benefit from formality to create a 'sense of substantive fairness and common aim that leads to greater levels of commitment' (p.454). Our findings that indicate that full-time and trade union members in SMEs are more likely to associate with bullying and harassment places further emphasis on the importance of policies and processes that are by nature embedded in formality. In considering bullying and harassment, autocracy and an absence of fairness and formality are clear risks for SMEs, especially when a lack of autonomy, excessive work demands, absence of clearly defined roles and manager/employer support is found wanting. 
This research demonstrates that there is much to be gained by SMEs embracing baseline understanding of bullying and harassment and ensuring policy, training and good practice take place in tackling work-related stressors that are associated with bullying and harassment. Whether these strategies are instigated by a HR specialist or embraced by generic managers and owners/managers matters not; what is significant is that SMEs recognise their similarities to larger organisations in terms of bullying and harassment, and this requires engagement and action. Yet, this should be considered with caution; as Woodrow and Guest (2013) found when investigating HR best practice and bullying, it did not lead to the intended results. This was because HR specialists perceived managers lacked the requisite skills, motivation and time to implement policy effectively. While Woodrow and Guest's (2013) research was conducted in a healthcare setting, there is strong evidence to suggest that HR practices have much to do with bullying and harassment beyond the simple rhetoric of policy (Fevre et al., 2011; Lewis and Rayner, 2003). As such, SMEs with or without a HR specialist need to demonstrate a connectedness between policy and action from owners/managers.

Contemporary research on bullying has mainly focused on large-scale employers traditionally equipped with policies, HR functions, occupational health and trade union representation, and therefore, the organisational correlates and associated factors of bullying have previously not been generalised to SMEs (Baillien et al., 2011b). This article reports on the constructs of bullying and harassment behaviours and work-related stressor factors across the conventional spectrum of SME classifications, and thus broadens understanding of how they may be related, and considers the implications for practice and practice in the context of these organisations.

\section{Funding}

The author(s) received no financial support for the research, authorship and/or publication of this article.

\section{References}

Ashkanasy NM (2002) Studies of cognition and emotion in organisations: Attribution, affective events, emotional intelligence and perception of emotion. Australian Journal of Management 27(1): 11-20.

Atkinson C, Mallett O and Wapshott R (2014) 'You try to be a fair employer': Regulation and employment relationships in medium-sized firms. International Small Business Journal. Epub ahead of print 17 July. DOI: $10.1177 / 0266242614541992$.

Bacon N, Hoque K and Siebert S (2013) Family Business People Capital. London: Institute for Family Business.

Baillien E, Neyens I, De Witte H, et al. (2009) A qualitative study on the development of workplace bullying: Towards a three way model. Journal of Community and Applied Psychology 19(1): 1-16.

Baillien E, De Cuyper N and De Witte H (2011a) Job autonomy and workload as antecedents of workplace bullying: A two-wave test of Karasek's job demand control model for targets and perpetrators. Journal of Occupational and Organizational Psychology 84(1): 191-208.

Baillien E, Neyens I and De Witte H (2011b) Organizational correlates of workplace bullying in small-and medium-sized enterprises. International Small Business Journal 29(6): 610-625.

Baillien E, Rodríguez-Muñoz A, De Witte H, et al. (2011c) The demand-control model and target's reports of bullying at work: A test within Spanish and Belgian blue-collar workers. European Journal of Work and Organizational Psychology 20(2): 157-177.

Baillien E, Rodríguez-Muñoz A, Van den Broeck A, et al. (2011d) Do demands and resources affect target's and perpetrators' reports of workplace bullying? A two-wave cross-lagged study. Work \& Stress 25(2): $128-146$.

Balducci C, Cecchin M and Fraccaroli F (2012) The impact of role stressors on workplace bullying in both victims and perpetrators, controlling for personal vulnerability factors: A longitudinal analysis. Work \& Stress 26(3): 195-212.

Beale D and Hoel H (2011) Workplace bullying and the employment relationship: Exploring questions of prevention, control and context. Work, Employment \& Society 25(1): 5-18. 
Bentley T, Catley B, Gardner D, et al. (2009) Understanding stress and bullying in New Zealand workplaces. Final Report to Health Research Council Steering Committee, Auckland, December 17, 2009.

Boso N, Story VM and Cadogan JW (2013) Entrepreneurial orientation, market orientation, network ties, and performance: Study of entrepreneurial firms in a developing economy. Journal of Business Venturing 28(6): 708-727.

Branch S, Murray J and Ramsay C (2012) Inquiry into Workplace Bullying. Canberra, ACT, Australia: House of Representatives Committee, No. 89, Parliament of Australia.

Brodsky CM (1976) The Harassed Worker. Lexington, MA: D.C. Heath and Company.

Chang SJ, Van Witteloostuijn A and Eden L (2010) From the editors: Common method variance in international business research. Journal of International Business Studies 41(2): 178-184.

Chay YW (1993) Social support, individual differences and well-being: A study of small business entrepreneurs and employees. Journal of Occupational and Organizational Psychology 66(4): 285-302.

Cocker F, Martin A, Scott J, et al. (2012) Psychological distress and related work attendance among smallto-medium enterprise owner/managers: Literature review and research agenda. International Journal of Mental Health Promotion 14(4): 219-236.

Cohen J, Cohen P, West SG, et al. (2014) Applied Multiple Regression/Correlation Analysis for the Behavioral Sciences (3rd edn). New York: Routledge.

Cooper C and Cartwright S (1997) An intervention strategy for workplace stress. Journal of Psychosomatic Research 43(1): 7-16.

Cox T (1993) Stress research and stress management: Putting theory to work. HSE Contract Research Report No. 61/1993. Sudbury: HSE Books.

Cox A, Rickard C and Tamkin P (2012) Work Organisation and Innovation. Dublin, OH: European Foundation for the Improvement of Living and Working Conditions.

D'Cruz P and Noronha E (2011) The limits to workplace friendship: Managerialist HRM and bystander behaviour in the context of workplace bullying. Employee Relations 33(3): 269-288.

De Cuyper N, Baillien E and De Witte H (2009) Job insecurity, perceived employability and targets' and perpetrators' experiences of workplace bullying. Work \& Stress 23(3): 206-224.

Dundon T, Grugulis I and Wilkinson A (1999) Looking for the black-hole: Non-union relations in a SME. Employee Relations 22(3): 251-266.

Edwards JA, Webster S, Van Laar D, et al. (2008) Psychometric analysis of the UK Health and Safety Executive's Management Standards work-related stress indicator tool. In: British academy of management annual conference, Harrogate, 10-12 September.

Einarsen S (2000) Harassment and bullying at work: A review of the Scandinavian approach. Aggression and Violent Behaviour 5(4): 379-401.

Einarsen S and Skogstad A (1996) Bullying at work: Epidemiological findings in public and private organizations. European Journal of Work and Organizational Psychology 5(2): 185-201.

Einarsen S, Hoel H, Zapf D, et al. (2011) The concept of bullying and harassment at work: The European tradition. In: Einarsen S, Hoel H, Zapf D, et al. (eds) Bullying and Harassment in the Workplace: Developments in Theory Research and Practice. London: CRC Press, pp.3-39.

Einarsen S, Raknes BI and Matthiesen SB (1994) Bullying and harassment at work and their relationship to work environment quality: An exploratory study. European Journal of Work and Organizational Psychology 4(4): 381-401.

Emdad R, Alipour A, Hagberg J, et al. (2013) The impact of bystanding to workplace bullying on symptoms of depression among women and men in industry in Sweden: An empirical and theoretical longitudinal study. International Archives of Occupational and Environmental Health 86(6): 709-716.

Equality Act (2010) Equality Act 2010. Available at: http://www.legislation.gov.uk/ukpga/2010/15/pdfs/ ukpga_20100015_en.pdf (accessed 18 October 2014).

European Commission (EC) (2003) Small and medium-sized enterprises (SMEs): What is an SME? Available at: http://ec.europa.eu/enterprise/policies/sme/facts-figures-analysis/sme-definition (accessed 18 September 2014).

Fevre R, Nichols T, Prior G, et al. (2009) Fair treatment at work report: Findings from the 2008 survey. Employment Relations Research Series No. 103. London: Department for Business, Innovation and Skills. 
Fevre R, Lewis D, Robinson A, et al. (2011) Insight into Ill-Treatment in the Workplace: Patterns, Causes and Solutions. Cardiff: School of Social Sciences, Cardiff University.

Fevre R, Lewis D, Robinson A, et al. (2012) Trouble at Work. London: Bloomsbury Academic Press.

Fevre R, Robinson A, Jones T, et al. (2010) Researching workplace bullying: The benefits of taking an integrated approach. International Journal of Social Research Methodology 13(1): 71-85.

Fevre R, Robinson A, Lewis D, et al. (2013) The ill-treatment of employees with disabilities in British Workplaces. Work, Employment \& Society 27(2): 288-307.

Field A (2009) Discovering Statistics Using SPSS (3rd edn). London: Sage.

Forth J, Bewley H and Bryson A (2006) Small and Medium Enterprises: Findings from the 2004 Workplace Employment Relations Survey. London: Department of Trade and Industry.

Giorgi G, Ando M, Arenas A, et al. (2013) Exploring personal and organizational determinants of workplace bullying and its prevalence in a Japanese sample. Psychology of Violence 3(2): 185-197.

Hair JF, Jr, Black WC, Babin BJ, et al. (2010) Multivariate Data Analysis: A Global Perspective (7th edn). Upper Saddle River, NJ: Pearson.

Harney B and Dundon T (2006) Capturing complexity: Developing an integrated approach to analysing HRM in SMEs. Human Resource Management Journal 16(1): 48-73.

Harvey M, Tredawy DC and Heames JT (2007) The occurrence of bullying in global organizations: A model and issues associated with social/emotional contagion. Journal of Applied Social Psychology 37(11): 2576-2599.

Hatfield E, Cacioppo JT and Rapson RL (1993) Emotional contagion: Current directions. Psychological Science 2(3): 96-99.

Hauge LJ, Skogstad A and Einarsen S (2007) Relationships between stressful work environments and bullying: Results of a large representative study. Work \& Stress 21(3): 220-242.

Health and Safety Executive (HSE) (1995) Stress at Work - A Guide for Employers (HS(G) 116). Sudbury: HSE Books.

Health and Safety Executive (HSE) (2008) Working Together to Reduce Stress at Work. Sudbury: HSE Books. Available from: http://www.hse.gov.uk/stress/standards/ (accessed 18 September 2014).

Hoel H and Beale D (2006) Workplace bullying, psychological perspectives and industrial relations: Towards a contextualized and interdisciplinary approach. British Journal of Industrial Relations 44(2): 239-262.

Hoel H and Cooper CL (2000) Destructive Conflict and Bullying at Work. Manchester: Manchester School of Management, University of Manchester Institute of Science and Technology.

Hoel H, Lewis D and Einardottir E (2014) The Ups and Downs of LGBs Workplace Experiences: Discrimination, Bullying and Harassment of Lesbian, Gay and Bisexual Employees in Britain. Manchester: Manchester University.

Hogh A, Hoel H and Carneiro IG (2011) Bullying and employee turnover among healthcare workers: A threewave prospective study. Journal of Nursing Management 19(6): 742-751.

Ikeda T, Nakata A, Takahashi M, et al. (2009) Correlates of depressive symptoms among workers in smalland-medium-scale manufacturing enterprises in Japan. Journal of Occupational Health 51(1): 26-37.

Jackson SE (1983) Participation in decision making as a strategy for reducing job-related strain. Journal of Applied Psychology 69(3): 546-547.

Jones JR, Huxtable CS, Hodgson JT, et al. (2003) Self-Reported Work-Related Illness in 2001/02: Results from a Household Survey. Sudbury: HSE Books.

Jones T, Robinson A, Fevre R, et al. (2011) Workplace assaults in Britain: Understanding the influence of individual and workplace characteristics. British Journal of Criminology 51: 159-178.

Karasek R (1979) Job demands, job decision latitude, and mental strain: Implications for job redesign. Administrative Science Quarterly 24(2): 285-308.

Kickul J (2001) When organizations break their promises: Employee reactions to unfair processes and treatment. Journal of Business Ethics 29(4): 289-307.

Kitching J (2015) Between vulnerable compliance and confident ignorance: Small employers, regulatory discovery practices and external support networks. International Small Business Journal. Epub ahead of head 3 February. DOI: 10.1177/0266242615569325.

Kitching J, Kašperová E and Collis J (2015) The contradictory consequences of regulation: The influence of filing abbreviated accounts on UK small company performance. International Small Business Journal 33(7): 671-688. 
Kline P (2000) The Handbook of Psychological Testing. London: Routledge.

Lai Y, Saridakis G and Blackburn R (2015) Job stress in the United Kingdom: Are small and medium sized enterprise and large enterprises different? Stress and Health 31(3): 222-235.

Leon-Perez JM, Medina FJ, Arenas A, et al. (2015) The relationship between interpersonal conflict and workplace bullying. Journal of Managerial Psychology 30(3): 250-263.

Lewis D (1999) Workplace bullying - Interim findings of a study in further and higher education in Wales. International Journal of Manpower 20(1/2): 106-118.

Lewis D and Rayner C (2003) Bullying and human resource management: A wolf in sheep's clothing? In: Einarsen S, Hoel H, Zapf D, et al. (eds) Bullying and Emotional Abuse in the Workplace: International Perspectives in Research and Practice. London: Taylor and Francis, pp.370-382.

Lewis D (2004) Bullying at work: The impact of shame among university and college lecturers. British Journal of Guidance and Counseling 32(3): 281-300.

Lewis D and Gunn RW (2007) Workplace bullying in the public sector: Understanding the racial dimension. Public Administration an International Quarterly 83(3): 641-665.

Leymann H (1996) The content and development of mobbing at work. European Journal of Work \& Organizational Psychology 5(2): 165-184.

Lutgen-Sandvik P and Tracy SJ (2012) Answering five key questions about workplace bullying: How communication scholarship provides thought leadership for transforming abuse at work. Management Communication Quarterly 26(1): 3-47.

Lutgen-Sandvik P, Tracy SJ and Alberts JK (2007) Burned by bullying in the American Workplace: Prevalence, perception, degree and impact. Journal of Management Studies 44(6): 837-862.

Mackay CJ, Cousins R, Kelly PJ, et al. (2004) 'Management standards' and work-related stress in the UK: Policy background and science. Work \& Stress 18(2): 91-112.

Marlow S and Patton D (1993) Managing the employment relationship in the smaller firm: Possibilities for human resource management. International Small Business Journal 11(4): 57-64.

Marlow S and Patton D (2002) Minding the gap between employers and employees. Employee Relations 24(5): 523-539.

Matthiesen SB (2006) Bullying at work: Antecedents and outcomes. PhD Thesis, Department of Psychosocial Science, University of Bergen, Bergen.

Matthiesen SB and Einarsen S (2004) Psychiatric distress and symptoms of PTSD among victims of bullying at work. British Journal of Guidance and Counseling 32(3): 335-356.

Notelaers G, Baillien E, De Witte H, et al. (2012) Testing the strain hypothesis of the demand control model to explain severe bullying at work. Economic and Industrial Democracy 34(1): 69-87.

Notelaers G, De Witte H and Einarsen S (2010) A job characteristics approach to explain workplace bullying. European Journal of Work and Organizational Psychology 19(4): 487-504.

O'Regan N and Ghobadian A (2004) Testing the homogeneity of SMEs: The impact of size on managerial and organizational processes. European Business Review 16(1): 64-77.

Podsakoff PM, MacKenzie SB, Lee JY, et al. (2003) Common method biases in behavioral research: A critical review of the literature and recommended remedies. Journal of Applied Psychology 88(5): 879-903.

Pyper D and McGuiness F (2015) Employment Tribunal Fees. London: Briefing Paper 07081 House of Commons.

Rayner C (1997) Incidence of workplace bullying. Journal of Community and Applied Social Psychology 7(3): 199-208.

Rayner C, Hoel H and Cooper C (2002) Workplace Bullying. London: Taylor and Francis.

Reknes I, Einarsen S, Knardahl S, et al. (2014) The prospective relationship between role stressors and new cases of self-reported workplace bullying. Scandinavian Journal of Psychology 55(1): 45-52.

Salin D (2015) Risk factors of workplace bullying for men and women: The role of the psychosocial and physical work environment. Scandinavian Journal of Psychology 56(1): 69-77.

Salin D and Hoel H (2011) Organisational causes of workplace bullying. In: Einarsen S, Hoel H, Zapf D, et al. (eds) Bullying and Harassment in the Workplace: Developments in Theory Research and Practice. London: CRC Press, pp.227-244. 
Saridakis G, Munoz Torres R and Johnstone S (2013) Do human resource practices enhance organizational commitment in SMEs with low employee satisfaction? British Journal of Management 24(3): 445-458.

Saundry R and Wibberley G (2014) Workplace Dispute Resolution and the Management of Individual Conflict - A Thematic Analysis of Five Case Studies. London: Acas.

Schneider KT, Pryor JB and Fitzgerald LF (2011) Sexual harassment research in the United States. In: Einarsen S, Hoel H, Zapf D, et al. (eds) Bullying and Harassment in the Workplace: Developments in Theory, Research and Practice. London: CRC Press, pp.245-265.

Sheehan M (2014) Human resource management and performance: Evidence from small and medium-sized firms. International Small Business Journal 32(5): 545-570.

Skogstad A, Torsheim T, Einarsen S, et al. (2011) Testing the work environment hypothesis of bullying on a group level of analysis: Psychosocial factors as precursors of observed workplace bullying. Applied Psychology: An International Review 60(3): 475-495.

Spector PE (1986) Perceived control by employees: A meta-analysis of studies concerning autonomy and participation at work. Human Relations 39(11): 1005-1016.

Storey DJ, Saridakis G, Sen-Gupta S, et al. (2010) Linking HR formality with employee job quality: The role of firm and workplace size. Human Resource Management Journal 49(2): 305-329.

Tepper BJ (2000) Consequences of abusive supervision. Academy of Management Journal 43(2): 178-190.

Taylor Nelson Soffres (TNS) Ltd (2008) Fair Treatment at Work Survey - Technical Report. London: TNS.

Van Wanrooy B, Bewley H, Bryson A, et al. (2013) The 2011 Workplace Employment Relations Study: First Findings. London: Department for Business, Innovation and Skills.

Vartia M (1996) The sources of bullying - Psychological work environment and organizational climate. European Journal of Work \& Organizational Psychology 5(2): 203-214.

Verreynne M-L, Parker P and Wilson M (2011) Employment systems in small firms: A multilevel analysis. International Small Business Journal 31(4): 405-431.

Woodrow C and Guest DE (2013) When good HR gets bad results: Exploring the challenge of HR implementation in the case of workplace bullying. Human Resource Management Journal 24(1): 38-56.

Zapf D, Einarsen S, Hoel H, et al. (2003) Empirical findings on bullying in the workplace. In: Einarsen S, Hoel H, Zapf D, et al. (eds) Bullying and Emotional Abuse in the Workplace: International Perspectives in Research and Practice. London: Taylor \& Francis, pp.103-126.

Zapf D, Knorz C and Kulla M (1996) On the relationship between mobbing factors, and job content, social work environment, and health outcomes. European Journal of Work \& Organizational Psychology 5(2): $215-237$.

\section{Author biographies}

Paul Jones is Professor of Entrepreneurship at the International Centre for Transformational Entrepreneurship at Coventry University. He has over 20 years experience of work in the Higher Education sector and has published widely in entrepreneurship and small business management.

Phil Megicks is Director of the Plymouth Graduate School of Management, Plymouth University, UK. He has published widely on various management and strategy issues in SMEs, particularly in the professional services sector. His interest in SME employment relations matters stems from a long-standing recognition of their importance in the delivery of service quality, and the significance of staff satisfaction and engagement in ensuring that effective organisational strategies are devised and implemented.

Duncan Lewis is Professor of Management at the Graduate School of Management, Plymouth University. He has spent over 20 years researching workplace bullying and has been co-investigator on two large scale ESRC funded representative studies into bullying and ill-treatment. He is currently advising on two studies of bullying in Ireland and Canada as well as working with the UK NHS on finding solutions to bullying and harassment in health and social care. 